\title{
The floppy mitral valve Study of incidence, pathology, and complications in surgical, necropsy, and forensic material
}

\author{
M. J. DAVIES, B. P. MOORE, AND M. V. BRAIMBRIDGE \\ From the Department of Pathology, St. George's Hospital Medical School; Department of Cardiothoracic \\ Surgery, Brook General Hospital; and Department of Cardiothoracic Surgery, St. Thomas's Hospital, \\ London
}

SUMMARY In the study of 1984 routine hospital necropsies the mitral valve was examined from the left atrium in the intact heart with a pressure head of water in the left ventricle. The valve was graded from grade $O$ (normal) to grade 4: grade 1, expansion of a small part of one cusp only; grade 2, over one-third of the posterior cusp or one-half of the anterior cusp expanded, with intact chordae; grade 3, ruptured chordae; grade 4, chordal fusion to ventricular wall. The frequency of grade 2 to 4 floppy valves rose with age with an overall incidence of 3.9 per cent in men and 5.2 per cent in women. Grade 1 floppy valves have no clinical significance. Grade 2 floppy valves were found to be associated with auscultatory signs but often only contributed to cardiac failure or were coincidental findings. Grade 3 and 4 floppy valves were direct causes of death from bacterial endocarditis and/or severe mitral regurgitation.

The surgical series of floppy valves showed that chordal rupture was the event which most commonly made operation necessary in middle age: in a minority this was caused by bacterial endocarditis. Dilatation of the annulus was an important contributory factor but can produce significant mitral regurgitation without chordal rupture, particularly in inherited connective tissue disorders such as the Marfan syndrome.

Forensic necropsies confirm that sudden death occurs in patients with floppy valves. The majority have grade 3 or 4 floppy valves and presumably significant mitral regurgitation. A minority have minimal valve involvement and the mechanism of death is unexplained.

The exact magnitude of the risk for any patient with a floppy valve of developing bacterial endocarditis, or chordal rupture leading to significant mitral regurgitation, or of dying suddenly, is not known but must be very low considering the frequency of the valve lesion.

The essential pathology of the floppy mitral valve is weakening of the central fibrous core allowing cusp expansion and chordal elongation to occur. The weakness of the collagen is in part genetically determined, in part age related. Identical changes occur in the tricuspid valve, and in the aortic root, leading to aortic regurgitation. Similar pathological changes are well recognised in other mammals, particularly the aged dog.

The best name has not yet been decided for the entity known as the floppy valve (Read et al., 1965), redundant cusp syndrome (Hill et al., 1974), billowing sail deformity (Oka and Angrist, 1961; Bittar and Sosa, 1968), or ballooning mitral cusp Behar et al., 1967). These names reflect the expansion of mitral cusp area and elongation of

Received for publication 6 May 1977 chordae which allow prolapse of the cusp into the atrium in ventricular systole, eventually resulting in mitral regurgitation. The terminology used by pathologists stresses the degenerative nature of the disease: the terms myxomatous (Read et al., 1965; Aslam et al., 1970), myxoid (Kern and Tucker, 1972), and mucinous degeneration (Frable, 1969) of the mitral valve are all in use. Further difficulty arises with the number of clinical terms in use for mitral valve prolapse (Abrams, 1976), including 
midsystolic click-late systolic murmur syndrome (Barlow et al., 1963) and prolapsed mitral cusp (Criley et al., 1966). The floppy valve is probably the major cause of this syndrome, but in an unknown proportion of cases the syndrome is the result of ischaemic heart disease or a cardiomyopathy (Aranda et al., 1975; Jeresaty, 1975; Nutter et al., 1975; Verani et al., 1976).

The diverse names and the preoccupation of groups of workers with selected aspects of their material have hindered the elucidation of an overall picture of the natural history of the disease. In the present study, we have attempted to present a composite view by examining material from medical, surgical, morbid anatomical, and forensic sources.

\section{Material and methods}

Material for study was available from three separate and unrelated sources. Forty-four floppy valves excised at operation for mitral regurgitation were obtained from two cardiothoracic units. A survey of 1984 consecutive routine necropsies carried out during the same period in four general hospitals in London provided 90 further examples of floppy mitral valve of moderate to severe degree. Over a period of 5 years, particular search for cases of sudden, unexpected death with a floppy valve was initiated by Professor R. D. Teare, who provided 13 examples from forensic necropsies performed for H.M. Coroner.

(a) CLINICAL FEATURES OF SURGICAL CASES Of the 44 cases available for study, 31 were men and 13 women. The age range was wide, from 32 to 69 years (mean 51.4 years). Murmurs had been present for many years in some cases, the longest being 48 years, but 23 per cent had had a murmur for less than 1 year and 48 per cent for less than 5 years (Table 1). Symptoms had been present for days only or up to 18 years before operation, with a mean of $4 \cdot 1$ years. Four patients only were definitely known to have had a late systolic murmur or click; the remainder were recorded as having a pansystolic murmur when first seen by the clinician. Four patients had had proven bacterial endocarditis; 3 additional cases had had a presumptive diagnosis of bacterial infection of the valve. Three patients had skeletal stigmata of Marfan's syndrome; 1 patient had osteogenesis imperfecta. Two patients were known to have had atrial septal defects of the secundum type.

\section{(b) CLINICAL FEATURES OF HOSPITAL}

\section{NECROPSY CASES}

The incidence of all grades of the floppy valve is shown in relation to age and sex in the 1984 necropsies in Table 2 . The relation between causes of death, age, sex, and clinical features of the 90 cases of significant degrees of the floppy valve is shown in Table 3. Floppy valves were considered to be the direct cause of death when present as the only discernible cause of left ventricular failure or when death resulted from bacterial endocarditis. Floppy valves were regarded as a possible contributory cause of death when associated with left ventricular failure, but with additional ischaemic heart disease, chronic bronchitis, or systemic hypertension. Deaths from, for example, carcinoma of the bronchus were recorded as having no relation to the floppy valve.

Table 1 Surgical series: length of known history of cardiac murmur

\begin{tabular}{lccccccccccccc}
\hline Duration in years & $<1$ & $1-5$ & $6-10$ & $11-15$ & $16-20$ & $21-25$ & $26-30$ & $31-35$ & $36-40$ & $41-45$ & $46-50$ & Total & 2 \\
\hline No. & 10 & 11 & 5 & 6 & 2 & 2 & 3 & 2 & 2 & 0 & 1 & 44 & 2 \\
\hline
\end{tabular}

Table 2 Routine necropsy series: sex and age incidence of all grades of floppy valve

\begin{tabular}{|c|c|c|c|c|c|c|c|c|c|}
\hline Men: Age at death (y) & $<40$ & $40-49$ & $50-59$ & & $60-69$ & $70-79$ & $80-89$ & $90+$ & All ages \\
\hline $\begin{array}{l}\text { Total no. of necropsies } \\
\text { Grade of valve abnormality }\end{array}$ & $\begin{array}{r}88 \\
0 \\
0 \\
0 \\
0\end{array}$ & $\begin{array}{r}108 \\
8 \\
0 \\
0 \\
0\end{array}$ & $\left.\begin{array}{r}154 \\
8 \\
3 \\
0 \\
0\end{array}\right\}$ & $1.9 \%$ & $\left.\begin{array}{r}323 \\
18 \\
13 \\
2 \\
1\end{array}\right\} 5 \cdot 0 \%$ & $\left.\begin{array}{r}320 \\
20 \\
16 \\
4 \\
1\end{array}\right\} 6.6 \%$ & $\left.\begin{array}{r}102 \\
3 \\
1 \\
3 \\
0\end{array}\right\} 3.9 \%$ & $\left.\begin{array}{c}16 \\
5 \\
0 \\
0 \\
0\end{array}\right\} 0$ & $\left.\begin{array}{r}1111 \\
62 \\
33 \\
9 \\
2\end{array}\right\} 3.9 \%$ \\
\hline Women: Age at death (y) & $<40$ & $40-49$ & $50-59$ & & $60-69$ & $70-79$ & $80-89$ & $90+$ & All ages \\
\hline $\begin{array}{l}\text { Total no. of necropsies } \\
\text { Grade of valve abnormality }\end{array}$ & $\left.\begin{array}{c}67 \\
2 \\
0 \\
1 \\
0\end{array}\right\} 1 \cdot 5 \%$ & $\left.\begin{array}{c}85 \\
2 \\
1 \\
0 \\
0\end{array}\right\} 1 \cdot 2 \%$ & $\left.\begin{array}{r}106 \\
3 \\
1 \\
0 \\
0\end{array}\right\}$ & $0.94 \%$ & $\left.\begin{array}{r}171 \\
10 \\
11 \\
1 \\
0\end{array}\right\} 7 \cdot 0 \%$ & $\left.\begin{array}{r}269 \\
10 \\
13 \\
4 \\
0\end{array}\right\} 6 \cdot 3 \%$ & $\left.\begin{array}{r}134 \\
7 \\
5 \\
5 \\
0\end{array}\right\} 7 \cdot 5 \%$ & $\left.\begin{array}{c}41 \\
5 \\
3 \\
1 \\
0\end{array}\right\} 9 \cdot 8 \%$ & $\left.\begin{array}{r}873 \\
39 \\
34 \\
12 \\
0\end{array}\right\} 5 \cdot 2 \%$ \\
\hline
\end{tabular}


Table 3 Necropsy series: clinical features related to age and sex

\begin{tabular}{|c|c|c|c|c|c|c|c|c|c|c|c|c|c|c|c|c|c|c|c|c|c|c|c|}
\hline \multirow[b]{3}{*}{ Age } & \multicolumn{10}{|l|}{ Men } & \multicolumn{13}{|c|}{ Women } \\
\hline & \multicolumn{5}{|c|}{ Grade 2} & \multicolumn{5}{|c|}{ Grade 3 to 4} & \multicolumn{6}{|c|}{ Grade 2} & \multicolumn{7}{|c|}{ Grade 3 to 4} \\
\hline & $\begin{array}{ll}50-6 \\
59 & 6\end{array}$ & $\begin{array}{l}60- \\
69\end{array}$ & $\begin{array}{l}70- \\
79\end{array}$ & $\begin{array}{l}80- \\
89\end{array}$ & $90+$ & $\begin{array}{l}50-6 \\
59\end{array}$ & $\begin{array}{l}60- \\
69\end{array}$ & $\begin{array}{l}70- \\
79\end{array}$ & $\begin{array}{l}80- \\
89\end{array}$ & $90+$ & $\begin{array}{l}40- \\
49\end{array}$ & $\begin{array}{l}50- \\
59\end{array}$ & $\begin{array}{l}60- \\
69\end{array}$ & $\begin{array}{l}70- \\
79\end{array}$ & $\begin{array}{l}80- \\
89\end{array}$ & $90+$ & $\begin{array}{r}<44 \\
4\end{array}$ & $\begin{array}{l}40- \\
49\end{array}$ & $\begin{array}{l}50- \\
59\end{array}$ & $\begin{array}{l}60 \\
69\end{array}$ & $\begin{array}{l}70 \\
79\end{array}$ & $\begin{array}{l}80 \\
89\end{array}$ & $90+$ \\
\hline Total no. of cases & 31 & & 16 & 1 & 0 & 0 & 3 & 5 & 3 & 0 & 1 & 1 & 11 & 13 & 5 & 3 & 1 & 0 & 0 & 1 & 4 & 5 & 1 \\
\hline Murmur recorded & $\begin{array}{ll}3 & 1 \\
81 \cdot 8 \%\end{array}$ & & 12 & 1 & - & $\begin{array}{l}0 \\
100 \%\end{array}$ & & 5 & 3 & - & $\begin{array}{l}1 \\
67 \cdot 4^{\circ}\end{array}$ & & 6 & 8 & 4 & 3 & $\begin{array}{l}1 \\
91 \cdot 7 \%\end{array}$ & - & - & 1 & 4 & 4 & 1 \\
\hline Cardiac failure present & $\begin{array}{l}2 \\
46 \cdot 7 \%\end{array}$ & & 6 & 0 & - & $\begin{array}{l}0 \\
81 \cdot 8^{\circ}\end{array}$ & & 5 & 3 & - & $47 \cdot 0^{\circ}$ & & 5 & 6 & 4 & 1 & $83.3 \%$ & - & - & 1 & 4 & 4 & 1 \\
\hline $\begin{array}{l}\text { Floppy valve direct } \\
\text { cause of death }\end{array}$ & $\begin{array}{l}0 \\
9 \cdot 1 \%\end{array}$ & & 1 & 0 & - & $\begin{array}{ll}0 \\
27 \cdot 3 \%\end{array}$ & & 0 & 1 & - & $\begin{array}{l}0 \\
8.8 \%\end{array}$ & & 0 & 1 & 1 & 1 & $150.0 \%$ & - & - & 0 & 3 & 2 & 0 \\
\hline $\begin{array}{l}\text { Floppy valve possible } \\
\text { contribution to death }\end{array}$ & $36.4 \%$ & & 6 & 0 & - & $\begin{array}{l}0 \\
63.6 \%\end{array}$ & $\begin{array}{l}1 \\
\%\end{array}$ & 5 & 1 & - & $35.3^{\circ}$ & $\begin{array}{l}0 \\
\%\end{array}$ & 4 & 5 & 3 & 0 & $\begin{array}{l}0 \\
41 \cdot 7 \%\end{array}$ & & - & 1 & 1 & 2 & 1 \\
\hline $\begin{array}{l}\text { Death totally unrelated } \\
\text { to floppy valve }\end{array}$ & $\frac{1}{54.5 \%}$ & & 9 & 1 & - & $\begin{array}{l}0 \\
9 \cdot 1 \%\end{array}$ & & 0 & 1 & - & $\begin{array}{l}1 \\
55.9\end{array}$ & & 7 & 7 & 1 & 2 & $8 \cdot 3 \%$ & - & - & 0 & 0 & 1 & 0 \\
\hline
\end{tabular}

Clinical data extracted from the patients' notes included age, sex, blood pressure readings, presence and nature of any murmur, and the presence of cardiac failure. The causes of death as found at necropsy were recorded. Family history was not sought other than that recorded in the clinical notes: previous medical history was taken as recorded in the clinical notes.

\section{(c) FORENSIC NECROPSY MATERIAL}

The material has been exclusively drawn from necropsies carried out for H.M. Coroner and all were examples of sudden unexpected death, within minutes, of patients who had not seen their medical practitioner for some weeks. The search was only undertaken to determine if any appreciable number of patients with floppy valves died suddenly without other apparent cause. Cases of floppy valves with a clear and definite alternative cause of death were not included in this study. No analysis of the exact number of cases of sudden death in the population from which they are taken was possible, but only 13 examples of the floppy valve were encountered in
5 years, compared with an average of 250 cases of ischaemic heart disease with sudden death annually. All cases were screened for the presence of drugs.

The histories of forensic necropsy cases were obtained from the Coroner's Officer and where possible the patients' general practitioners. Of the 13 cases, 5 had no history of any cardiac disease; 8 were known to have had cardiac murmurs for periods of 4 to 25 years, and 4 of these had in the past been treated for cardiac failure.

\section{Pathological methods}

(a) SURGICAL MATERIAL

At the time of operation the surgeon specifically looked for and recorded the incidence of chordal rupture. The size of the mitral annulus was roughly assessed by inspection at operation and by the size of prosthetic valve (Starr or Björk-Shiley) inserted. The use of a number 4 Starr mitral valve was taken to indicate a dilated mitral annulus. After excision each valve was pinned flat and photographed (Fig. 1). Material for routine microscopy was

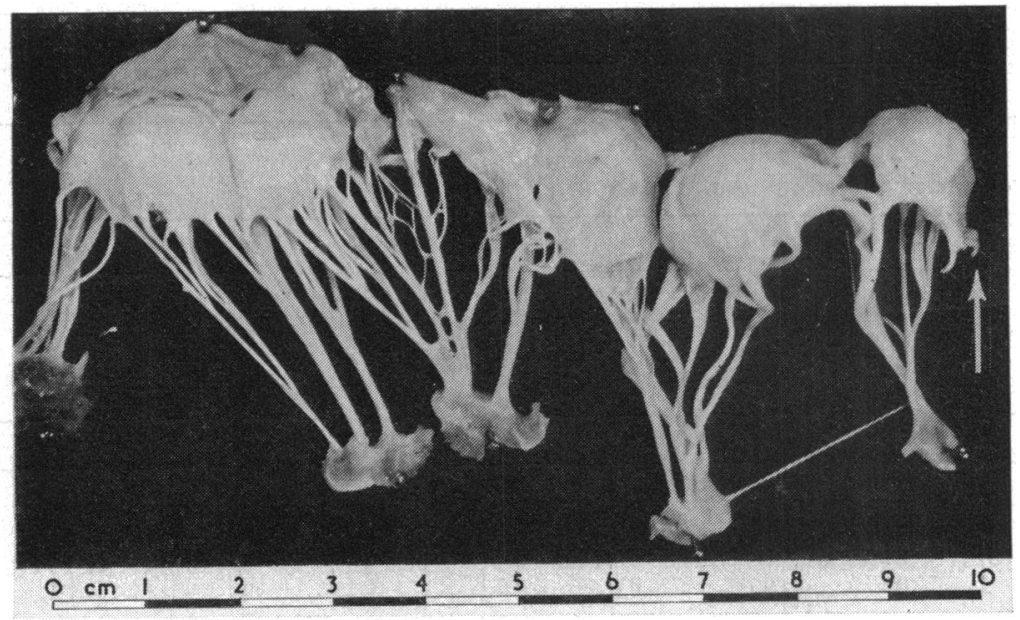

Fig. 1 Surgically excised floppy valve pinned flat for examination. Anterior cusp shows chordal elongation with expansion of free margin of the cusp. Posterior cusp shows expansion and doming of whole cusp with ruptured chordae (arrow). 
fixed in 10 per cent formol saline, for estimation of acid mucopolysaccharides in acetone, and for electron microscopy in glutaraldehyde. Sections for light microscopy were stained by the elastic-Van Gieson technique to show elastic and collagen. Sections were examined for connective tissue mucopolysaccharides by staining with alcian blue/PAS at $p \mathrm{H} 3.0$ (Mowry and Winkler, 1956). Material fixed for electron microscopy was post-fixed in osmium tetroxide for one hour before routine embedding and cutting. Thin sections were examined in the Zeiss EM9S electron microscope.

\section{(b) NECROPSY MATERIAL}

Before opening the ventricle, the mitral valve was inspected from the left atrium and ruptured chordae noted. The left ventricle was filled with water via a rubber tube introduced through the aorta, and the mitral valve closed either by squeezing the ventricle by hand or by tying off the aorta and applying high pressure from a mains water tap; inspection of the closed mitral valve from the left atrium then allows easy identification of cusp prolapse (Fig. 2, 3, 4). After opening the left ventricle, the mitral ring circumference was measured in centimetres. In all 1984 hearts the anterior and posterior cusps of the mitral valve were graded as follows: grade 0 , within normal limits; grade 1, expansion of only a small portion of one cusp; grade 2, at least one-third of the posterior

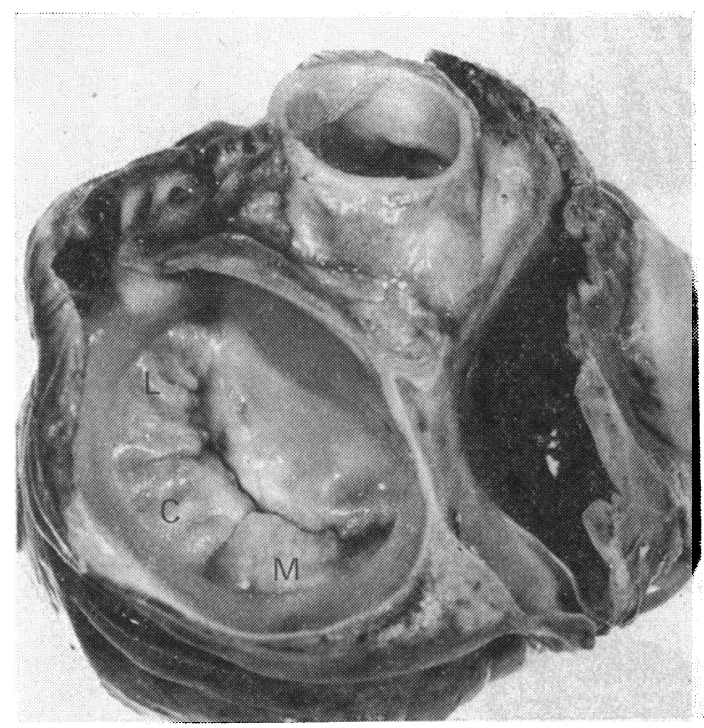

Fig. 2 Normal mitral valve fixed by pressure in closed position and viewed from left atrium. The three scallops of the posterior cusp are visible ( $L$, lateral; $C$, central; $M$, medial). There is no cusp prolapse.

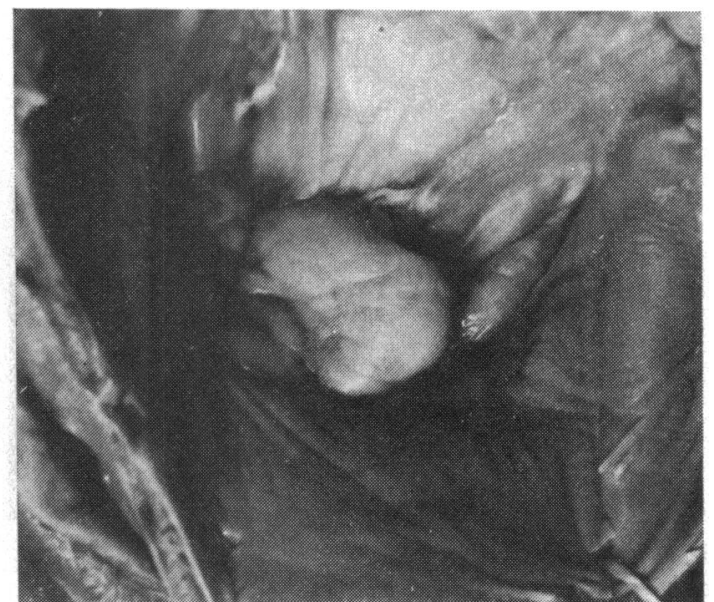

Fig. 3 Examination of mitral valve in unfixed intact heart. Valve viewed from left atrium with water at mains pressure in left ventricle. Posterior cusp prolapses into the atrium and water streams under its free edge. (Man aged 80. Discharged from Army in 1916 at age 20 with murmur which persisted. Death from carcinoma.)

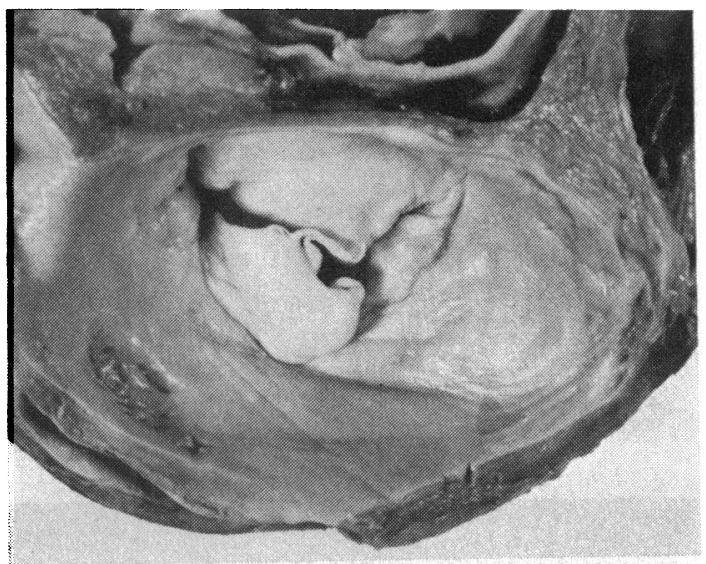

Fig. 4 Same heart as Fig. 3, fixed with mitral valve in closed position to show prolapsed middle segment of posterior cusp with ruptured chordae.

cusp or one-half of the anterior cusp involved, but with intact chordae (Fig. 5); grade 3, floppy valves complicated by chordal rupture (Fig. 6); grade 4, chordae fused to the ventricular wall (Fig. 7). Changes in the tricuspid valve were similarly noted. Subsequently the heart was dissected, isolated left and right ventricular weights were measured, and the presence of any additional pathology in the heart was noted. After routine fixation in formol saline, all valves were examined histologically in sections stained by the elastic-Van Gieson technique, alcian 


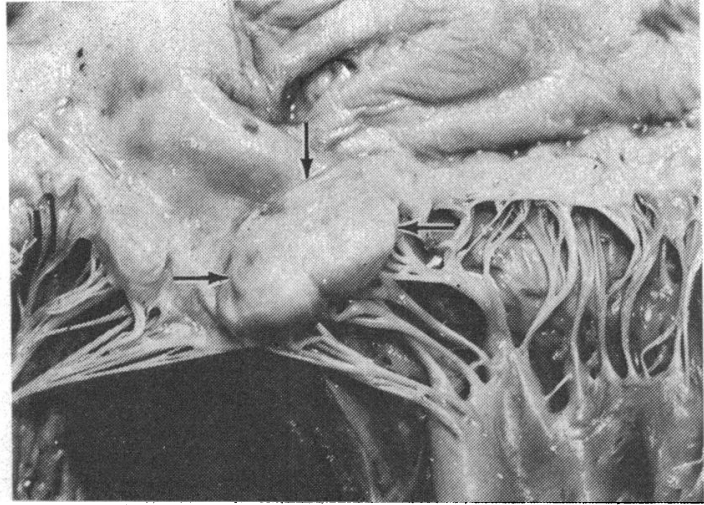

Fig. 5 Grade 2 floppy valve at necropsy. One half only of anterior cusp is expanded and ballooned (arrows). Posterior cusp is unaffected.

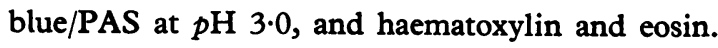

\section{Results}

PATHOLOGICAL APPEARANCES

The macroscopical appearances of the floppy valve are characteristic and, with practice, easily recognised in both surgical and necropsy material. In the latter, recognition of a significant abnormality was best made from the left atrium before opening the ventricle. Indeed the best definition of the floppy valve is sufficient elongation of chordae and expansion of cusp area to allow prolapse into the atria on applying a pressure load to close the valve. Ruptured chordae can also be noted without risk of artefactual cutting.

The valve cusp was increased in area and in both longitudinal and transverse dimensions leading to
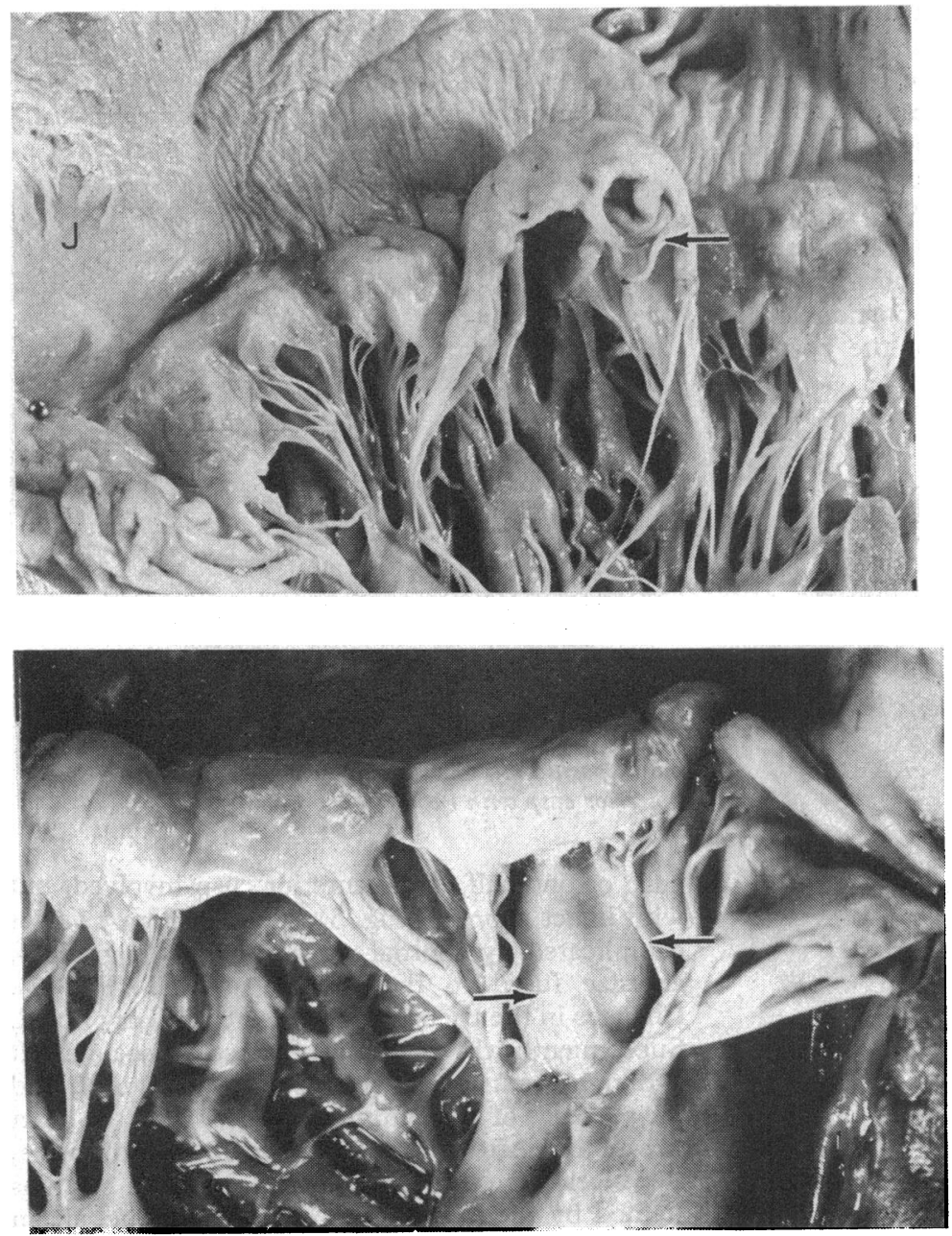

Fig. 6 Grade 3 floppy valve at necropsy. Middle segment of posterior cusp is domed into left atrium with several chordae ruptured (arrow). An atrial jet lesion is present ( $\mathcal{F}$ ).

Clinical diagnosis was significant mitral regurgitation.

Fig. 7 Grade 4 floppy valve at necropsy. Chordae of middle segment of posterior cusp fused into fibrous mass adherent to ventricular endocardium (arrows). 
folding and convolution (Fig. 8) and upward doming of the cusp towards the atrium. Partial involvement of the posterior cusp involved the central (Fig. 4) or medial scallop, more rarely than the lateral scallop alone. Partial involvement of the anterior cusp was more common at the medial commissure (Fig. 5). More severe changes involved the whole anterior or posterior cusp or both. Chordal elongation, tortuosity, and thinning were usually present. Chordal rupture (grade 3 ) led to an accentuation of upward doming of the cusp. Ruptured chordae appeared filiform or, with time, became blunt-ended or folded back to adhere to the cusp surface. Chordae with areas of thinning, presumably preceding rupture, were seen (Fig. 9). Focal areas of thickening had developed on the mural ventricular endocardium in most cases of grade 2 or 3 floppy valves; these occasionally enlarge sufficiently to entrap and fix chordae (grade 4) (Fig. 7), as recognised by Salazar and Edwards (1970). Bacterial endocarditis was also a cause of chordal rupture and cusp destruction (Fig. 10, 11).

In some instances the valve appeared translucent and gelatinous, but in the majority very considerable secondary fibrosis had occurred on the atrial aspect of the cusp making the valve white and opaque; in the past this has caused misinterpretation and erroneous diagnosis of chronic rheumatic disease (Fig. 8). Elongated chordae also undergo secondary fibrosis with considerable thickening (Fig. 8), again simulating chronic rheumatic disease. The mitral ring circumference was normal, moderately,
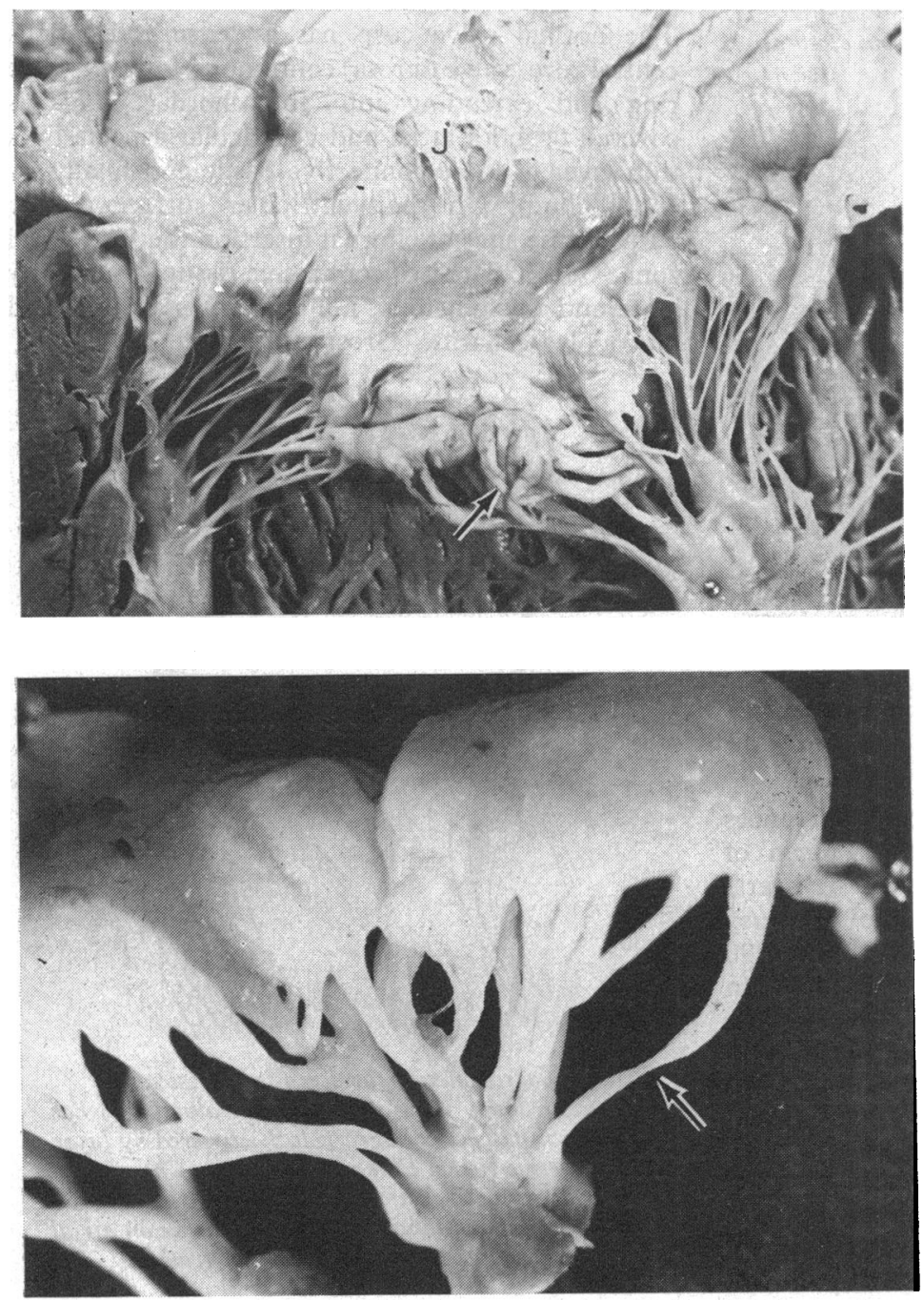

Fig. 8 Necropsy specimen showing severe involvement of anterior cusp. Chordae elongated, tortuous, and thickened, simulating rheumatic disease (arrow). Extensive jet lesion in left atrium ( $(\mathcal{F})$.

Fig. 9 Surgically excised floppy valve. Posterior cusp is expanded, domed, and opaque. The chordae are thickened and one (arrow) shows a narrow 'waist' at one point. Chordal rupture present elsewhere. 


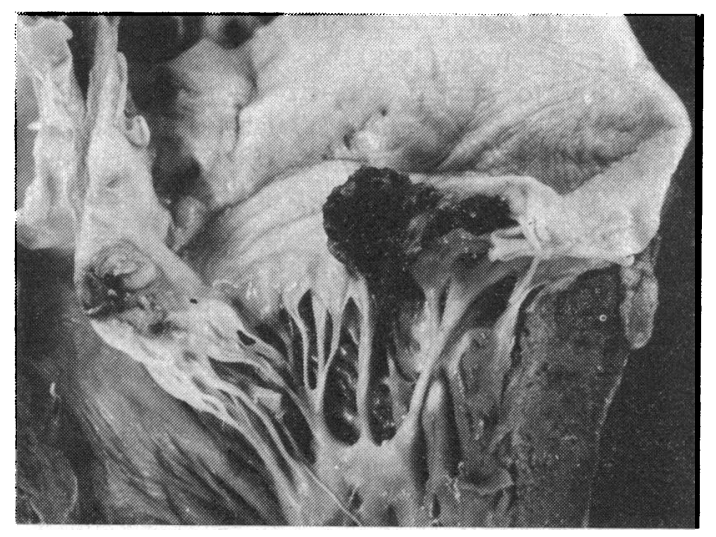

Fig. 10 Necropsy specimen showing bacterial endocarditis affecting a floppy valve. Gross destruction of cusp with ruptured chorade (grade 3). (Woman aged 62 with pansystolic murmur. Death from cerebral haemorrhage from mycotic aneurysm.)

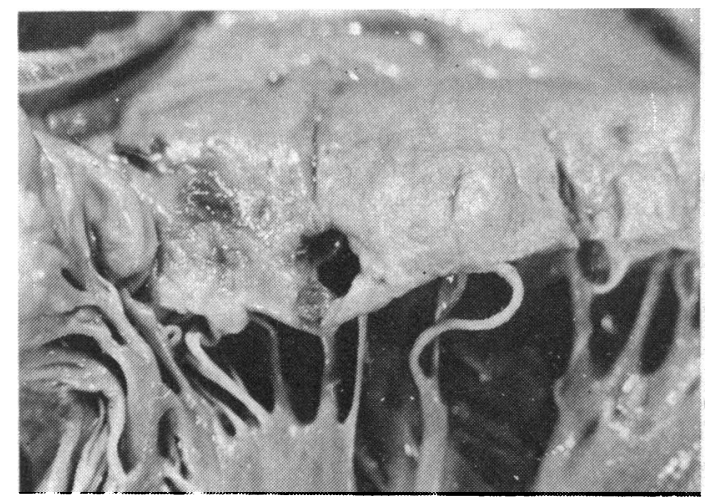

Fig. 11 Necropsy specimen showing floppy valve with perforated posterior cusp. (Mild mitral regurgitation with previously treated bacterial endocarditis. Sudden death in cardiac failure.)

or grossly increased. The ring circumferences ranged from $6 \mathrm{~cm}$ to $13.6 \mathrm{~cm}$, with a mean of $8.0 \mathrm{~cm}$. The mitral ring circumference in hearts without any valve abnormality in the necropsy series was 5.3 to $10.3 \mathrm{~cm}$ (mean $7.8 \mathrm{~cm}$ ). Of the 90 cases of floppy mitral valve (grade 2 and above) in the hospital necropsy series, 6 had a mitral ring circumference over $10.3 \mathrm{~cm}(6.7 \%)$. Valve calcification was virtually never present, only being seen if coexistent senile mitral ring calcification was present (3 cases, $3.3 \%$ ). The papillary muscles were normal.

In the necropsy series overall $6 \cdot 1$ per cent of all hearts showed an area of ischaemic scarring in excess of $2 \mathrm{~cm}$ in size. Of the 90 hearts with significant floppy valves, 4 only had coexistent myocardial ischaemic damage $(4.4 \%)$. Isolated left ventricular weights showed a considerable range in the 90 cases with floppy mitral valves. Forty-seven were below the upper limit of normal for our laboratory $(185 \mathrm{~g})$. Forty-five lay between 185 and $300 \mathrm{~g}$, and 8 were in excess of $300 \mathrm{~g}$. No histological evidence was found for coexistent cardiomyopathy though the 6 cases with dilated mitral annuli had isolated left ventricular weights over $300 \mathrm{~g}$ and a large left ventricular cavity.

In the surgical series mitral valves known to be derived from patients with other stigmata of Marfan's syndrome showed the same general range of macroscopical appearances as other floppy valves, with the exception that translucent rather fragile valves were more common in young subjects.

\section{MICROSCOPICAL FINDINGS}

The normal valve cusp has a dense collagenous central core (valve fibrosa) continuous with the valve ring and extending into the chordae. This is covered on both atrial and ventricular aspects by a thin layer of loose connective tissue and finally by endothelium. On the ventricular surface of the cusps at the sites of chordal insertion the superficial zone (ventricularis) of connective tissue is normally loose and myxomatous, i.e. contains stainable acid mucopolysaccharide (Gross and Kugel, 1931).

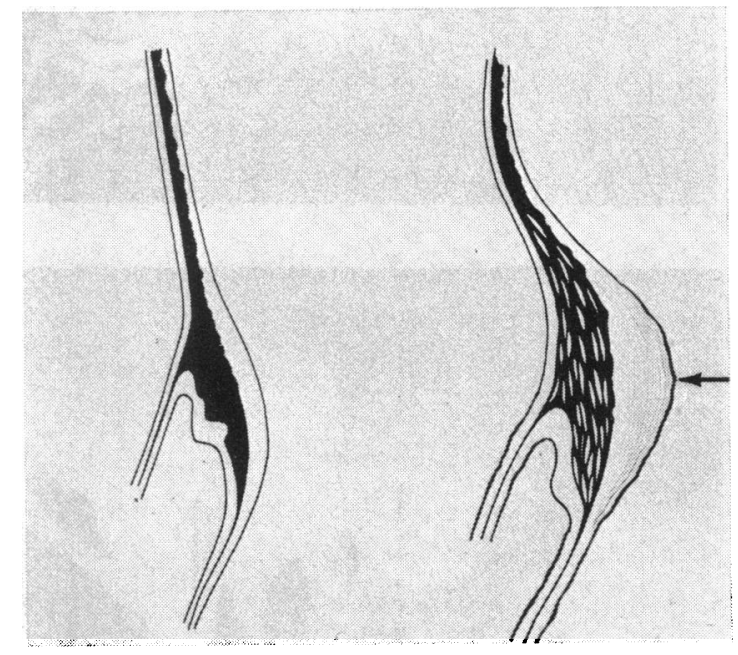

Fig. 12 Diagrammatic representation of essential pathology of floppy valve. The normal valve (left) has dense central mass of collagen (black) covered by layer of loose connective tissue. Floppy valve (right) has widened fibrosa with cystic spaces and less dense collagen. Superficial layer of connective tissue on atrial surface thickened as result of mechanical trauma (arrow). 
In contrast in the floppy valve the collagen of the central valve fibrosa is abnormal. Large areas show apparent loss of fibrous tissue with individual collagen bundles fragmented, coiled, and disrupted. Maximal destruction occurs around sites of chordal insertion but the changes may extend into the body of the cusp. Areas of destruction of collagen usually show easily demonstrable pools of acid mucopolysaccharide in which residual strands of collagen lie. These histological changes must not be confused with the rather loose myxomatous connective tissue normally found in the ventricularis zone near the chordae. Histological examination must be made of sections passing exactly through the long axis of the valve where the topography can be seen and the fibrosa identified. Over the atrial surface of the cusp a superficial zone of dense laminated collagen forms which often contrasts with the 'moth eaten' fibrosa. Within this zone of superficial dense fibrosis small areas of fibrin deposition occur on the surface, and the lesion as a whole results from friction of the excessively mobile cusps. Ultrastructural study does not do more than confirm the fragmentation of collagen and occurrence of pools of connective tissue mucin. We have not observed abnormal periodicity in collagen fibrils.

In the absence of a history of bacterial endocarditis the valve cusps are not vascularised nor do they contain chronic inflammatory cells. Both features enable histological distinction to be made from chronic rheumatic valve disease. A further point of distinction is the absence of calcification in the floppy mitral valve.

Small isolated areas of collagen destruction even within the fibrosa are very common in grade 1 floppy valves in otherwise normal hearts. The diagnosis of significant degree of floppy valve is made by naked eye observation of sufficient expansion of cusp or chordae to allow prolapse under pressure and microscopy to show major dissolution of the valve fibrosa in the prolapsed segment. Random histological sections without detailed examination of the intact fresh heart are useless.

\section{CLINICAL CORRELATION WITH MORBID ANATOMICAL FINDINGS}

\section{(a) Surgical material}

The onset of symptoms ranged from abrupt, requiring operation within a month, to gradual increase of disability over years. The mean period between onset of symptoms and operation was $4 \cdot 1$ years. The incidence of chordal rupture was high (77\%) with the posterior cusp most commonly involved (Table 4). Of the 44 patients, 24 required a No. 4 valve prosthesis indicating a large mitral annulus. Only 1 patient had chordal fusion to the posterior cusp at operation.

\section{(b) Hospital necropsy material}

In the hospital necropsy series trivial degrees of the floppy mitral valve syndrome (grade 1 ) were very common. Review of the clinical records showed that only 15 per cent of these patients had had any

Table 4 Surgical series: incidence of ruptured chordae

\begin{tabular}{llllll}
\hline & $\begin{array}{l}\text { Anterior Posterior } \\
\text { cusp }\end{array}$ & $\begin{array}{l}\text { Both } \\
\text { cusp }\end{array}$ & $\begin{array}{l}\text { Chordae } \\
\text { not ruptured }\end{array}$ & Total \\
\hline No. of cases & 10 & 24 & 2 & 8 & 44 \\
\hline
\end{tabular}
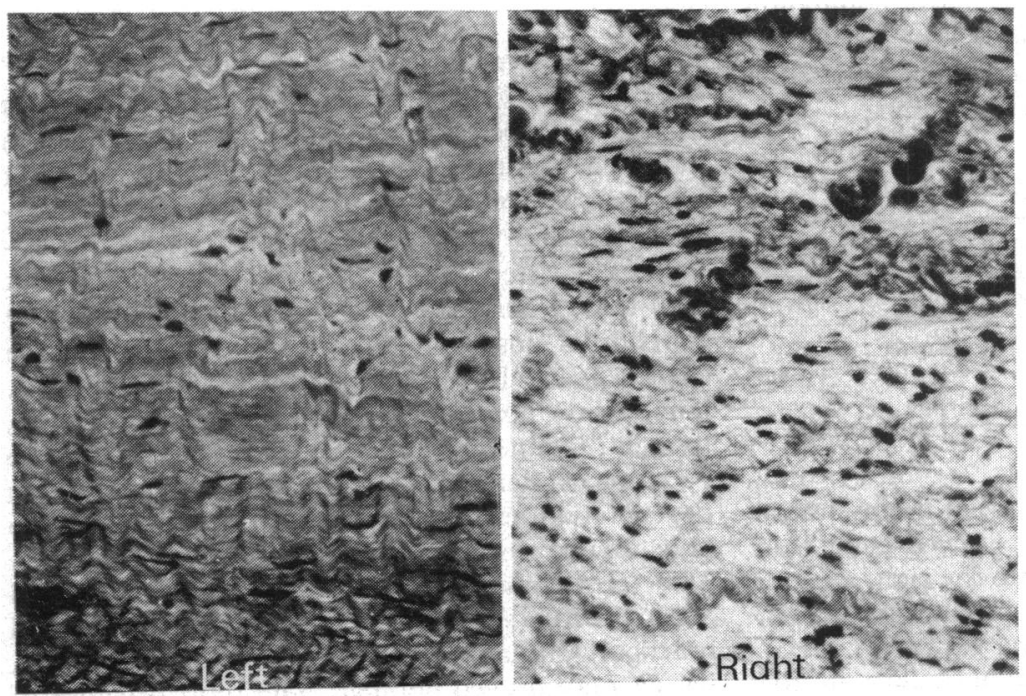

Fig. 13 Histological section $(\times 276)$ of the valve fibrosa stained by elastic Van Gieson technique (left, normal; right, floppy valve). The abnormal fibrosa has less densely packed collagen with areas of loose myxomatous tissue; collagen bundles appear broken and coiled. 
murmur and the lesion was not clinically significant. Grade 2 to 4 floppy mitral valves are potentially more serious and were found in 3.9 per cent of all men and 5.2 per cent of all women (Table 2). In 80.1 per cent of these patients, murmurs had been recorded. The incidence of floppy valves rose with age to a maximum of 5.5 per cent in the eighth decade in men, after which it apparently fell. In women there was a steady rise in incidence to a maximum of 10.0 per cent over the age of 90 .

The possible significance of the grade 2 floppy mitral valves in 67 patients without chordal rupture could be judged by the cause of death. Thirty-seven $(55.2 \%)$ died of non-cardiac disease, $24(35.8 \%)$ died of cardiac failure, but with additional causes including hypertension, chronic bronchitis, and ischaemic heart disease also present. Only 6 patients of the $67(9.0 \%)$ died of cardiac failure only attributable to the floppy mitral valve. In these 6 patients the mitral ring circumference ranged from $10 \mathrm{~cm}$ to $13.5 \mathrm{~cm}$, with a mean of $11.5 \mathrm{~cm}$.

The significance of grade 3 and 4 floppy valves was more clear cut. In 22 of the 23 patients, loud pansystolic murmurs were recorded in the clinical notes; there was no record of heart sounds in the other case. Nine of the patients $(39 \%)$ died directly from bacterial endocarditis or cardiac failure from mitral regurgitation because of the floppy valve; in 12 patients $(52 \%)$ death was from cardiac failure but with coexistent hypertension, ischaemic heart disease, or chronic bronchitis. In only 2 patients $(9 \%)$ was death the result of malignant disease and unrelated to the floppy valve.

The distribution of cusp expansion in grade 2 floppy valves and the anatomical sites of chordal rupture in grade 3 to 4 floppy valves are shown in Table 5. The posterior cusp is most commonly involved, with posterior chordae the most common site of rupture, though both cusps or, rarely, the anterior cusp alone can be affected.

Table 5 Necropsy series: pathological features

\begin{tabular}{|c|c|c|c|c|c|}
\hline \multicolumn{3}{|c|}{ Grade 2 (66 cases) } & \multicolumn{3}{|c|}{ Grade 3 to 4 (24 cases) } \\
\hline \multicolumn{3}{|c|}{ Expansion of cusps } & \multicolumn{3}{|c|}{ Ruptured chordae } \\
\hline Anterior & Posterior & Both & Anterior & Posterior & Both \\
\hline 3 & 44 & 19 & 5 & $17^{\star}$ & 2 \\
\hline
\end{tabular}

*Associated with bacterial endocarditis in 5 .

In many patients with grade 2 to 4 floppy mitral valves, the tricuspid valve also showed expansion of the cusp area with prolapse into the right atrium. The change maximally involved the anterior cusp. Of 67 patients with grade 2 mitral valves, $45(67 \%)$ had an equivalent degree of abnormality in the tricuspid valve. The 23 patients with grade 3 to 4 mitral valves showed a higher incidence, with at least one cusp of the tricuspid involved in $18(78 \%)$. One patient had ruptured chordae to the anterior cusp of the tricuspid valve. There was no clinical evidence to suggest that the tricuspid abnormalities were of any clinical significance.

\section{(c) Forensic necropsy material}

The 13 examples of unexpected death which could be ascribed to the floppy mitral valve had pathological findings listed in Table 6. Cases with ruptured chordae or bacterial endocarditis were likely to have had significant mitral regurgitation and their sudden death was, therefore, explicable. Four cases remained, 3 in young women, in which the mechanism and cause of sudden death was totally obscure. No histological evidence of ischaemic heart disease or cardiomyopathy was present.

Table 6 Forensic necropsies: pathological features

\begin{tabular}{llll}
\hline Sex & Age $(y)$ & Ruptured chordac & Associated pathology at necropsy \\
\hline F & 29 & 0 & 0 \\
F & 74 & Anterior & 0 \\
M & 54 & 0 & Old inferior infarct \\
M & 61 & 0 & 0 \\
F & 69 & Anterior & 0 \\
M & 79 & Posterior & Chronic bronchitis, hypertension \\
F & 68 & Posterior & Bacterial endocarditis \\
F & 37 & Posterior & 0 \\
F & 32 & 0 & 0 \\
F & 63 & Posterior & 0 \\
F & 26 & 0 & 0 \\
F & 64 & Posterior & Bacterial endocarditis \\
F & 54 & Both & 0 \\
\hline
\end{tabular}

\section{Discussion}

A generally acceptable name for the 'floppy valve' entity remains to be agreed (Abrams, 1976). The condition is certainly not new; a specimen was mounted in the Pathological Museum of St George's Hospital in 1936 under the name 'parachute deformity of the mitral valve'. A local tradition has existed for the use of this name, but it does lead to confusion with the congenital anomaly of chordal insertion into one papillary muscle (Shone et al., 1963) and has had to be suppressed. The term 'floppy valve' is gaining acceptance, though 'redundant cusp' is more accurate. The pathological names such as myxoid or myxomatous degeneration are less popular, stressing as they do only minor morphological features of the disease. The term 'blue valve syndrome' (McCarthy and Wolf, 1970), stressing the accumulation of acid mucopolysaccharides as shown by alcian blue stains, has also not proved popular. The term prolapse of 
the mitral cusp is purely descriptive in relation to echocardiograms or angiograms and may result from the cusp and chordal abnormality of the floppy valve, but also occurs with ischaemic papillary muscle damage (Aranda et al., 1975; Nutter et al., 1975) or in cardiomyopathy (Liedtke et al., 1973). The frequency of the lesion shown in this necropsy series is, however, so close to that of mitral valve prolapse in echocardiographic studies (Procacci et al., 1976) that floppy valve is likely to be the commonest cause of prolapse.

The floppy valve is essentially the result of a weak cusp fibrosa allowing stretching and expansion to occur. The clinical course suggests that this process may begin very early in life and progress extremely slowly if at all, or begin late in life with more rapid progression over a few years; intermediate varieties are common. The pathogenesis of the weakening of the collagen in the cusp fibrosa remains unknown. In part it is genetically determined; familial cases are well recognised (Hunt and Sloman, 1969; Shell et al., 1969; Shappell et al., 1973), and the floppy valve is an integral part of the generalised connective tissue weakness of Marfan's syndrome (McKusick, 1955; Miller and Pearson, 1959; Shankar et al., 1967; Bowers, 1969; Simpson et al., 1969; Murdoch et al., 1972). Other diseases associated with generalised connective tissue defect in which the floppy mitral valve is known to occur include osteogenesis imperfecta (Criscitiello et al., 1965; Wood et al., 1973), the Ehlers-Danlos syndrome (McKusick, 1966; Brandt et al., 1975), and pseudoxanthoma elasticum (Huang et al., 1967). The occurrence of the floppy valve in Marfan's syndrome has led to the suggestion that all cases are hereditary and, in the absence of other stigmata, are 'formes frustes' of the fully developed disease (Read et al., 1965). No familial trend emerged in our series, with the exception of one patient in the forensic necropsy series with a cousin in the surgical series. The usual family history taken for clinical notes is, however, not exhaustive; moreover, the condition has not been adequately diagnosed until recently.

The incidence of a floppy mitral valve at necropsy tends to rise with age; there is work (Bashey et al., 1967) to suggest that the collagen content of the human mitral valve falls with age. The evolution of the floppy mitral valve may, therefore, in part be a process analogous to the change seen in the skin with increasing age. An identical process occurs in aged dogs leading to mitral regurgitation (Pomerance and Whitney, 1970) and is known to occur in other mammals in advanced age (Whitney, 1975). Pomerance (1969) has previously recorded the high incidence of floppy valves in human geriatric necropsies.
While the necropsy data tend to suggest the lesion increases in severity with age, individual clinical case histories illustrate how benign and chronic the condition may be. The reported increased incidence with age in necropsy series could partly result from the greater ease of recognition in long-standing cases when secondary cusp fibrosis has occurred.

No other pathological process has been implicated and the valves are not vascularised, inflamed, or replaced by dense fibrous tissue as in chronic rheumatic disease. It is not clear whether the weakness of the fibrosa in the floppy valve is caused by weakness of the individual collagen fibres or by a decrease in total collagen. The morphological findings tend to support the former explanation and histological appearance of the floppy valve with its destruction of the fibrosa is easily distinguishable from that of chronic rheumatic disease with its increased collagen. The superficial fibrosis over the atrial surface of the cusp and on the chordae as a result of friction does lead to a superficial resemblance to chronic rheumatic disease. Rheumatic disease, however, leads to cusp retraction not expansion.

If the total collagen content of the valve fibrosa is diminished, it is not known if synthesis is diminished or lysis is increased. Morphological similarity between the focal areas of collagen loss in affected chordae and the action of elastase on collagen in vitro lends some support to a 'lytic' theory (Selzer et al., 1967; Caulfield et al., 1969; Sanders et al., 1971). It is probable that accumulation of connective tissue mucins is secondary to the abnormality of collagen and elastic synthesis or breakdown (Shappell et al., 1973) and no abnormal mucopolysaccharide has been found (Sherman et al., 1970). This point is of some importance since accumulation of abnormal mucopolysaccharides within valve tissue in Hurler's syndrome (gargoylism) (Berenson and Geer, 1963) may lead to disruption of the fibrosa, with a picture closely analogous to the floppy valve. Our own ultrastructural studies and those of others (Kern and Tucker, 1972) have confirmed the haphazard arrangement of collagen fibrils, with disruption or fragmentation, but the characteristic periodicity of the individual fibrils remains normal.

Our own work and that of others (Sanders et al., 1971; McKay and Yacoub, 1973) supports the view that degeneration of collagen within the central core of the chordae is responsible for chordal rupture, though it is claimed that increased chordal tension resulting from the enlarged area of the cusp may play a contributory role. In a small proportion of cases, chordal rupture results from superimposed bacterial endocarditis, which may occur in 
the floppy valve syndrome (Lachman et al., 1975), and is well shown in the necropsy study by Pomerance (1969), in the present necropsy and surgical series, and in a prospective study of patients with the late systolic murmur syndrome (Allen et al., 1974). Infection begins on the atrial surfaces of the cusps in floppy valves where incorporation of fibrin is often seen as a secondary friction lesion.

Our hospital necropsy series shows that minor degrees (grade 1) of floppy valve are very common (Table 3) but are of no clinical significance. More severe grades $(2,3)$ of floppy valve are potentially more serious and were found in up to 7 per cent of older individuals, though this figure is higher than that recorded by Pomerance (1969) in a necropsy series. Our necropsy series suggests that the incidence rises with age and is a little higher in women, though our surgical series is predominantly male. Any hospital series is selected, contains a disproportionate number of older patients, and does not accurately reflect the incidence in the young or very old. Our necropsy data are in keeping with a number of recent echocardiographic studies (Procacci et al., 1976). In addition, the necropsy study shows that the floppy valve has a spectrum of severity from partial to whole cusp involvement. This spectrum could well explain the very different incidences reported in different echocardiographic studies, in some of which partial involvement of the posterior cusp may not have been detected. Our necropsy study supports the view that floppy valves of some degree are present in between 5 and 18 per cent of the population (Brown et al., 1975; Markeiwicz et al., 1975; Procacci et al., 1976). The necropsy data do not support the great preponderance of women recorded in these echo studies, though the incidence was higher in young and old women than in men. Only one echo study (Higgins et al., 1976) has so far described the common occurrence of valve prolapse in middle-aged men, but clearly echo studies are needed to confirm or refute the necropsy evidence of a rise in incidence with age.

The actual clinical significance of floppy valves found at necropsy must be questioned. In the hospital necropsy series, moderately severe floppy valves, but without chordal rupture, were directly responsible for death from cardiac failure as a result of mitral regurgitation only in a small minority, could have contributed to cardiac failure in about a third of patients, and had no clinical significance in over half of patients (Table 3 ). In contrast, more severely affected floppy valves with chordal rupture caused death directly in 39 per cent of patients and contributed to cardiac failure in 52 per cent.
Dilatation of the mitral annulus in association with the floppy valve will potentiate mitral regurgitation (Bulkley and Roberts, 1975) but was only found in a small minority of cases in our necropsy series. Our necropsy data do not show any difference in the occurrence of ischaemic (coronary artery) disease between those cases with and without floppy valves. We have not confirmed the association of absence of the left circumflex artery with floppy valve (Gentzler et al., 1975).

The surgical series shows an age range somewhat below that of the necropsy cases. Analysis of the reasons for their clinical presentation with severe mitral regurgitation at a younger age suggests that chordal rupture is the common precipitating event, but that bacterial endocarditis and annular dilatation can also be responsible. The last is particularly associated with generalised connective tissue disorders such as Marfan's syndrome. Review of the surgical cases shows the onset of symptoms to be either gradual or sudden. Some patients were known to have had systolic murmurs for up to 47 years, but the majority had significant mitral regurgitation when first seen by the surgeon. The striking feature is that only 10 per cent were known to have had late systolic murmurs or clicks before their first presentation, though this may reflect merely lack of recording or recognition at previous routine medical examination. In a prospective study of patients with late systolic murmurs (Allen et al., 1974), only one has so far had to have valve replacement for chordal rupture.

Sudden unexpected death has been increasingly reported in the late systolic murmur syndrome (Hancock and Cohn, 1966; Shell et al., 1969; Jeresaty, 1976) and in some cases necropsy has shown a floppy valve (Shappell et al., 1973). On the other hand, a prospective study of patients with isolated late systolic murmurs showed no increased risk of sudden death (Allen et al., 1974). This divergence of view may reflect the fact that a late systolic murmur has a number of causes. In perhaps a majority the cause is a floppy valve and some evidence for this view comes with the association of the late systolic murmur with minor skeletal abnormalities (Rizzon et al., 1973; Salomon et al., 1975). Other causes of a late systolic murmur include ischaemic papillary muscle damage, primary myocardial disease, and rheumatic mitral valve disease (Epstein and Coulshed, 1973; Jeresaty, 1975), and it is possible that the recorded sudden deaths came from patients with these conditions rather than those with floppy valves. In the present hospital necropsy series, half of the patients with severe degrees of floppy valve died suddenly, but only one of the moderately severe patients did. 
This, however, merely reflects the fact that patients with severe mitral regurgitation may die suddenly.

In the United Kingdom sudden death is likely to result in a necropsy outside the hospital by forensic pathologists working for H.M. Coroner. These cases would not appear in our hospital necropsy series. Specific search has, therefore, been made over the same period for grade 2 to 4 floppy valves thought to be the direct and only cause of sudden death. In forensic practice only 13 cases emerged, the majority with significant mitral regurgitation as a result of chordal rupture. There were, however, 4 cases, 3 in young women, with floppy valves but no chordal rupture, where no other cause for death was found. Thus, it seems likely that sudden death can be a complication of the floppy mitral valve with only minimal regurgitation, but the risk to an individual patient is very low. The mechanism remains to be elucidated, but atrial and ventricular arrhythmias are well known in patients with mitral valve prolapse (Winkle et al., 1975; Ritchie et al., 1976).

A number of cardiac abnormalities are known to be linked with the floppy valve. The link with Marfan's syndrome is the best recognised, the two conditions overlapping in cases of floppy valves with minor skeletal abnormalities (Rizzon et al., 1973). Some authors have recorded an association of aortic regurgitation with floppy mitral valves and suggested the existence of 'floppy' aortic cusps (McKay and Yacoub, 1973). The mechanism of aortic closure and competence is, however, entirely different from that of the mitral valve. Simple expansion of the aortic cusp area will not lead to regurgitation and we have no morphological proof that a floppy aortic valve occurs. We have 3 cases of floppy mitral valve with aortic regurgitation in our necropsy series; all had increased aortic root diameters and the link between aortic regurgitation and floppy mitral valves lies in an associated weakness of the connective tissues of the aortic root and of the mitral valve fibrosa. Two patients in the surgical series had mild aortic regurgitation at the time of their mitral operation without overt stigmata of Marfan's syndrome.

Atrial septal defects of the secundum variety may be associated with late systolic murmurs and clicks (McDonald et al., 1971; Littler et al., 1973) or with prolapse of the mitral cusp (Betriu et al., 1975; Leachman et al., 1976), and occasionally mitral regurgitation develops. The mitral valve abnormality may be rheumatic or a secondary haemodynamic effect (Okada et al., 1969), but we have seen two typical floppy valves associated with atrial septal defect in the surgical series and the association is well recorded (Hynes et al., 1974; Betriu et al., 1975).
While the present study identifies the risks and complications of the floppy valve, it does not and cannot accurately assess the magnitude of each risk. If it is assumed that the floppy valve is the most common cause of an isolated late systolic murmur, the work of Allen et al. (1974) suggests that the risk of each complication is very small. The most contentious point is the risk of sudden death in patients with minimal mitral regurgitation from a floppy valve without coronary artery or myocardial disease. Enough cases have been seen in forensic practice for the diagnosis to be acceptable in the Coroner's court as a cause of sudden death, but only the cases followed in great clinical detail, as by Shappell and his colleagues (1973), will provide scientific proof of the association.

There is a real need for a large-scale, long-term study of patients shown by echocardiography to have prolapse of a mitral cusp. Unfortunately only necropsy may actually show whether the cause is a floppy mitral valve, ischaemic papillary muscle, or cardiomyopathy, and provide information about the risk of sudden death in each group. Thus, determination of the actual incidence of each complication in relation to each cause of mitral cusp prolapse might require life-long follow-up and necropsy study.

\section{References}

Abrams, J. (1976). Mitral valve prolapse: a plea for unanimity. American Heart fournal, 92, 413-415.

Allen, H., Harris, A., and Leatham, A. (1974). Significance and prognosis of an isolated late systolic murmur: a 9- to 22-year follow up. British Heart fournal, 36, 525-532.

Aranda, J. M., Befeler, B., Lazzara, R., Embi, A., and Machado, H. (1975). Mitral valve prolapse and coronary artery disease: clinical, hemodynamic and angiographic correlations. Circulation, 52, 245-253.

Aslam, P. A., Eastridge, C. E., Bernhardt, H., and Pate, J. W. (1970). Myxomatous degeneration of cardiac valves. Chest, $57,535-539$.

Barlow, J. B., Pocock, W. A., Marchand, P., and Denny, M. (1963). The significance of late systolic murmurs. American Heart fournal, 66, 443-452.

Bashey, R. I., Torili, S., and Angrist, A. (1967). Age related collagen and elastin content of human heart valves. fournal of Gerontology, 22, 203-208.

Behar, V. S., Whalen, R. E., and McIntosh, H. D. (1967). The ballooning mitral valve in patients with the 'precordial honk' or 'whoop'. American fournal of Cardiology, 20, 789-795.

Berenson, G. S., and Geer, J. C. (1963). Heart disease in the Hurler and Marfan syndromes. Archives of Internal Medicine, 111, 58-69.

Betriu, A., Wigle, E. D., Felderhof, C. H., and McLoughlin, M. J. (1975). Prolapse of the posterior leaflet of the mitral valve associated with secundum atrial septal defect. American fournal of Cardiology, 35, 363-369.

Bittar, N., and Sosa, J. A. (1968). The billowing mitral valve leaflet-report on fourteen patients. Circulation, 38, 763-770. 
Bowers, D. (1969). Pathogenesis of primary abnormalities of the mitral valve in Marfan's syndrome. British Heart fournal, 31, 679-683.

Brandt, K. D., Sumner, R. D., Ryan, T. J., and Cohen, A. S. (1975). Herniation of mitral leaflets in Ehlers-Danlos syndrome. American Fournal of Cardiology, 36, 524-528.

Brown, O. R., Kloster, F. E., and De Mots, H. (1975). Incidence of mitral valve prolapse in the asymptomatic normal (abstract). Circulation, 51 -52, Suppl. II-77.

Bulkley, B. H., and Roberts, W. C. (1975). Dilatation of the mitral anulus. A rare cause of mitral regurgitation. American Fournal of Medicine, 59, 457-463.

Caulfield, J. B., Page, D. L., Kastor, J. A., and Sanders, C. A. (1969). Dissolution of connective tissue in ruptured chordae. Circulation, 40, Suppl. III, 57.

Criley, J. M., Lewis, K. B., Humphries, J. O., and Ross, R. S. (1966). Prolapse of the mitral valve-clinical and cineangiocardiographic findings. British Heart fournal, 28, 488-496.

Criscitiello, M. G., Ronan, J. A., Besterman, E. M. M., and Schoenwetter, W. (1965). Cardiovascular abnormalities in osteogenesis imperfecta. Circulation, 31, 255-262.

Epstein, E. J., and Coulshed, N. (1973). Phonocardiogram and apex cardiogram in systolic click-late systolic murmur syndrome. British Heart fournal, 35, 260-275.

Frable, W. J. (1969). Mucinous degeneration of the cardiac valves. Fournal of Thoracic and Cardiovascular Surgery, 58, 62-70.

Gentzler, R. D., Gault, J. H., Liedtke, A. J., McCann, W. D., Mann, R. H., and Hunter, A. S. (1975). Congenital absence of the left circumflex coronary artery in the systolic click syndrome. Circulation, 52, 490-496.

Gross, L., and Kugel, M. A. (1931). Topographic anatomy and histology of the valves in the human heart. American Fournal of Pathology, 7, 445-473.

Hancock, E. W., and Cohn, K. (1966). The syndrome associated with midsystolic click and late systolic murmur. American fournal of Medicine, 41, 183-196.

Higgins, C. B., Reinke, R. T., Gosink, B. B., and Leopold, G. R. (1976). The significance of mitral valve prolapse in middle aged and elderly men. American Heart fournal, 91, 292-296.

Hill, D. G., Davies, M. J., and Braimbridge, M. V. (1974). The natural history and surgical management of the redundant cusp syndrome (floppy mitral valve). Fournal of Thoracic and Cardiovascular Surgery, 67, 519-525.

Huang, S., Kumar, G., Steele, H. D., and Parker, J. O. (1967). Cardiac involvement in pseudoxanthoma elasticum. American Heart fournal, 74, 680-686.

Hunt, D., and Sloman, G. (1969). Prolapse of the posterior leaflet of the mitral valve occurring in eleven members of a family. American Heart fournal, 78, 149-153.

Hynes, K. M., Frye, R. L., Brandenburg, R. O., McGoon, D. C., Titus, J. L., and Giuliani, E. R. (1974). Atrial septal defect (secundum) associated with mitral regurgitation. American Fournal of Cardiology, 34, 333-338.

Jeresaty, R. M. (1975). Etiology of the mitral valve prolapseclick syndrome. American fournal of Cardiology, 36, 110-113.

Jeresaty, R. M. (1976). Sudden death in the mitral valve prolapse-click syndrome. American fournal of Cardiology, 37, 317-318.

Kern, W. H., and Tucker, B. L. (1972). Myxoid changes in cardiac valves: pathologic, clinical and ultrastructural studies. American Heart Fournal, 84, 294-301.

Lachman, A. S., Bramwell-Jones, D. M., Lakier, J. B., Pocock, W. A., and Barlow, J. B. (1975). Infective endocarditis in the billowing mitral leaflet syndrome. British Heart fournal, 37, 326-330.

Leachman, R. D., Cokkinos, D. V., and Cooley, D. A. (1976).
Association of ostium secundum atrial septal defects with mitral prolapse. American fournal of Cardiology, 38, 167-169.

Liedtke, A. J., Gault, J. H., Leaman, D. M., and Blumenthal, M. S. (1973). Geometry of left ventricular contraction in the systolic click syndrome. Characterisation of a segmental myocardial abnormality. Circulation, 47, 27-35.

Littler, W. A., Epstein, E. J., and Coulshed, N. (1973). Acute mitral regurgitation resulting from ruptured or elongated chordae tendineae. Quarterly fournal of Medicine, 42, 87-110.

McCarthy, L., and Wolf, P. L. (1970). Mucoid degeneration of heart valves-'blue valve' syndrome (abstract). American fournal of Cardiology, 25, 115.

McDonald, A., Harris, A., Jefferson, K., Marshall, J., and McDonald, L. (1971). Association of prolapse of posterior cusp of mitral valve and atrial septal defect. British Heart Fournal, 33, 383-387.

McKay, R., and Yacoub, M. (1973). Clinical and pathological findings in patients with 'floppy' valves treated surgically. Circulation, 47-48, Suppl. III, 63-73.

McKusick, V. A. (1955). The cardiovascular aspects of Marfan's syndrome: a heritable disorder of connective tissue. Circulation, 11, 321-342.

McKusick, V. A. (1966). Heritable Disorders of Connective Tissue, 3rd ed. Mosby, St. Louis.

Markeiwicz, W., Stoner, J., London, E., Hunt, S. A., and Popp, R. L. (1975). Mitral valve prolapse in one hundred presumably healthy females (abstract). Circulation, 51-52, Suppl. II-77.

Miller, R., and Pearson, R. J. (1959). Mitral insufficiency simulating aortic stenosis-report of an unusual manifestation of Marfan's syndrome. New England fournal of Medicine, 260, 1210-1213.

Mowry, R. W., and Winkler, C. H. (1956). The coloration of acidic carbohydrates. American fournal of Pathology, 32, 628-629.

Murdoch, J. L., Walker, B. A., Halpern, B. L., Kuzman, J. W., and McKusick, V. A. (1972). Life expectancy and causes of death in Marfan syndrome. New England fournal of Medicine, 286, 804-808.

Nutter, D. O., Wickliffe, C., Gilbert, C. A., Moody, C., and King, S. B. (1975). The pathophysiology of idiopathic mitral valve prolapse. Circulation, 52, 297-305.

Oka, M., and Angrist, A. (1961). Fibrous thickening with billowing sail distortion of the aging heart valve. Proceedings of the New York State Association Public Health Laboratory, $46,21$.

Okada, R., Glagov, S., and Lev, M. (1969). Relation of shunt flow and right ventricular pressure to heart valve structure in atrial septal defect. American Heart fournal, 78, 781-795.

Pomerance, A. (1969). Ballooning deformity (mucoid degeneration) of atrioventricular valves. British Heart fournal, 31, 343-351.

Pomerance, A., and Whitney, J. C. (1970). Heart valve changes common to man and dog: a comparative study. Cardiovascular Research, 4, 61-66.

Procacci, P. M., Savran, S. V., Schreiter, S. L., and Bryson, A. L. (1976). Prevalence of clinical mitral-valve prolapse in 1169 young women. New England fournal of Medicine, 294, 1086-1088.

Read, R. C., Thal, A. P., and Wendt, V. E. (1965). Symptomatic valvular myxomatous transformation (the floppy valve syndrome). Circulation, 32, 897-910.

Ritchie, J. L., Hammermeister, K. E., and Kennedy, J. W. (1976). Refractory ventricular tachycardia and fibrillation in a patient with the prolapsing mitral valve syndrome: successful control with overdrive pacing. American fournal of Cardiology, 37, 314-316.

Rizzon, P., Biasco, G., Brindicci, G., and Mauro, F. (1973). 
Familial syndrome of midsystolic click and late systolic murmur. British Heart fournal, 35, 245-259.

Salazar, A. E., and Edwards, J. E. (1970). Friction lesions of ventricular endocardium. Archives of Pathology, 90, 364-376.

Salomon, J., Shah, P., and Heinle, R. A. (1975). Thoracic skeletal abnormalities in idiopathic mitral valve prolapse. American fournal of Cardiology, 36, 32-36.

Sanders, C. A., Armstrong, P. W., Willerson, J. T., and Dinsmore, R. E. (1971). Etiology and differential diagnosis of acute mitral regurgitation. Progress in Cardiovascular Diseases, 14, 129-152.

Selzer, A., Kelly, J. J., Vannitamby, M., Walker, P. Gerbode, F., and Kerth, W. J. (1967). The syndrome of mitral insufficiency due to isolated rupture of the chordae tendineae. American fournal of Medicine, 43, 822-836.

Shankar, K. R., Hultgren, M. K., Lauer, R. M., and Diehl, A. M. (1967). Lethal tricuspid and mitral regurgitation in Marfan's syndrome. American fournal of Cardiology, 20, 122-128.

Shappell, S. D., Marshall, C. E., Brown, R. E., and Bruce, T. A. (1973). Sudden death and the familial occurrence of mid-systolic click, late systolic murmur syndrome. Circulation, 48, 1128-1134.

Shell, W. E., Walton, J. A., Clifford, M. E., and Willis, P. W. (1969). The familial occurrence of the syndrome of mid-late systolic click and late systolic murmur. Circulation, 39, 327-337.

Sherman, E. B., Char, F., Dungan, W. T., and TCampbell, G. S. (1970). Myxomatous transformation of the mitral valve producing mitral insufficiency. American fournal of Diseases of Children, 119, 171-175.

Shone, J. D., Sellers, R. D., Anderson, R. C., Adams, P., Lillehei, C. W., and Edwards, J. E. (1963). The developmental complex of 'parachute mitral valve', supravalvular ring of left atrium, subaortic stenosis and co-arctation of aorta. American fournal of Cardiology, 11, 714-725.

Simpson, J. W., Nora, J. J., and McNamara, D. G. (1969). Marfan's syndrome and mitral valve disease: acute surgical emergencies. American Heart fournal, 77, 96-99.

Verani, M. S., Carroll, R. J., and Falsetti, H. L. (1976). Mitral valve prolapse in coronary artery disease. American fournal of Cardiology, 37, 1-6.

Whitney, J. C. (1975). The spontaneous cardiovascular diseases of animals. In Pathology of the Heart, pp. 579-610. Ed. by A. Pomerance and M. J. Davies. Blackwell, Oxford.

Winkle, R. A., Lopes, M. G., Fitzgerald, J. W., Goodman, D. J., Schroeder, J. S., and Harrison, D. C. (1975). Arrhythmias in patients with mitral valve prolapse. Circulation, 52, 73-81.

Wood, S. J., Thomas, J., and Braimbridge, M. V. (1973). Mitral valve disease and open heart surgery in osteogenesis imperfecta tarda. British Heart fournal, 35, 103-106.

Requests for reprints to Professor M. J. Davies, Department of Histopathology, St George's Hospital Medical School, Cranmer Terrace, London SW17 0RE. 